\title{
Licenciamento Ambiental de Estradas de Terra
}

Environmental Licensing of Earth Roads

Licencia Ambiental de Caminos de Tierra

Juliana Pereira Siqueira

Graduanda, UNESP - Ilha Solteira/SP, Brasil. julianapsiiqueira@gmail.com

Jairo Salim Pinheiro de Lima Professor Doutor, UNESP - Ilha Solteira/SP, Brasil. jairo.lima@unesp.br

Elizete Aparecida Checon de Freitas Lima Professora Doutora, UNESP - Ilha Solteira/SP, Brasil. elizete.lima@unesp.br 


\title{
Revista Científica ANAP Brasil
}

\author{
ISSN 1984-3240 - Volume 13, número 31, 2020
}

\section{RESUMO}

Estradas e rodovias são importantes para a economia e o desenvolvimento. No Brasil, os transportes rodoviários abrigam $61 \%$ do volume de tráfego das cargas. Mas a maior extensão da malha rodoviária brasileira $(78,4 \%)$ é constituída por vias não pavimentadas: as estradas de terra. As estradas de terra são entendidas aqui como vias cuja superfície de tráfego é o próprio solo local ou revestimento primário, resultando de caminhos e trilhas primitivos sem observar os princípios de sustentabilidade. O presente trabalho é um estudo acerca dos instrumentos de licenciamento ambiental de estradas de terra adotados pelas unidades da federação (UF) brasileira, delimitando as normas jurídicas inerentes ao processo. Inicialmente, realizou-se uma consulta aos sites dos órgãos ambientais em cada UF, que foi complementada com ligações telefônicas. Para ampliar o acervo de informações foi elaborado, numa segunda etapa, um questionário com perguntas objetivas direcionadas aos gestores dos órgãos ambientais. 0 documento foi disponibilizado via formulários Google para as 27 UFs. Apenas 10 estados aderiram ao protocolo. Dentre as respostas cadastradas, apenas MG e SP não realizam o LA de estradas de terra. Por outro lado, à exceção do DF e do PA, as demais UFs que relataram realizar o licenciamento de estradas de terra, citaram a legislação que orienta o processo que, em alguns casos, apresentava caráter mais genérico. Dado o escopo de procedimentos e estudos ambientais obtidos, as normativas adotadas por ES e SC foram as que mais se aproximaram do propósito de ordenação do LA de estradas de terra.

PALAVRAS-CHAVE: Estradas de terra. Gestão ambiental. Licenciamento Ambiental.

\section{ABSTRACT}

Roads and highways are important for the economy and development. In Brazil, road transport is home to $61 \%$ of the volume of freight traffic. But the largest extension of the Brazilian road network (78.4\%) consists of unpaved roads: earth roads. Earth roads are understood here as roads whose traffic surface is the local soil itself or primary coating, resulting from primitive paths and trails without observing the principles of sustainability. The present work is a study about the environmental licensing instruments of earth roads adopted by the units of the Brazilian federation (UF), delimiting the legal norms inherent to the process. Initially, a consultation was carried out to the websites of environmental agencies in each UF, which was complemented with telephone calls. To expand the collection of information, a questionnaire with objective questions was prepared in a second stage, directed to the managers of environmental agencies. The document was made available via Google forms for the 27 UFs. Only 10 states adhered to the protocol. Among the answers registered, only MG and SP do not perform the EL of earth roads. On the other hand, with the exception of DF and PA, the other UFs that reported licensing earth roads cited the legislation that guides the process, which, in some cases, was more generic. Given the scope of environmental procedures and studies obtained, the regulations adopted by ES and SC were the ones that most closely approached the purpose of ordering EL of earth roads.

KEYWORDS: Earth roads. Environmental management. Environmental Licensing.

\section{RESUMEN}

Los caminos y las carreteras son importantes para la economía y el desarrollo. En Brasil, el transporte por carretera es responsable del $61 \%$ del volumen del tráfico de carga. Pero la mayor extensión de la red vial brasileña $(78,4 \%)$ consiste en caminos sin pavimentar: caminos de tierra. Las caminos de tierra se entienden aquí como caminos cuya superficie de tráfico es el propio suelo local o el revestimiento primario, resultante de caminos y senderos primitivos sin observar los principios de sostenibilidad. El presente trabajo es un estudio sobre los instrumentos de concesión de licencias ambientales de caminos de tierra adoptados por las unidades de la federación brasileña (UF), delimitando las normas legales inherentes al proceso. Inicialmente, se realizó una consulta a los sitios web de los organismos ambientales de cada UF, que se complementó con llamadas telefónicas. Para ampliar la recopilación de información, se preparó un cuestionario con preguntas objetivas, en una segunda etapa, dirigido a los gerentes de los organismos ambientales. El documento se puso a disposición a través de formularios de Google para las 27 UFs. Sólo 10 estados se adhirieron al protocolo. Entre las respuestas registradas, sólo MG y SP no realizan el LA de caminos de tierra. Por otra parte, con la excepción de DF y PA, las otras UF que informaron de la concesión de licencias por caminos de tierra, citaban la legislación que guía el proceso que, en algunos casos, era más genérico. Dado el alcance de los procedimientos y estudios ambientales obtenidos, los reglamentos adoptados por ES y SC fueron los que más se acercaron al propósito de ordenar la de caminos de tierra.

CONTRASENAS: Caminos de tierra. Gestión Ambiental. Licencia Ambiental. 


\section{Revista Científica ANAP Brasil}

ISSN 1984-3240 - Volume 13, número 31, 2020

\section{INTRODUÇÃO}

Nos primórdios do século XIX, a necessidade de integrar os polos produtivos precipitou o surgimento das primeiras rodovias no Brasil. A consolidação do modal rodoviário de transporte aconteceu concomitante ao processo de industrialização e consequente fomento da indústria automobilística. Por fim, o modal rodoviário no Brasil prevaleceu sobre os demais meios de transporte e se tornou a principal alternativa para a movimentação de pessoas e de cargas. E a relevância das estradas é confirmada pelo volume de cargas e passageiros transportados. No Brasil este fator alcança $61,1 \%$ e $95 \%$, respectivamente (CNT, 2020).

Mas a maior porção das estradas e rodovias brasileiras é desprovida de pavimento: as chamadas estradas de terra. Para o Departamento Nacional de Estradas de Rodagem (DNER, 2000), por exemplo, a malha rodoviária brasileira conta com $1.724 .929 \mathrm{~km}$ e 90,4\% deles não pavimentados. Para o Sistema Nacional de Viação (SNV, 2017), as rodovias nacionais contabilizam $1.720 .700 \mathrm{~km}$, dos quais $78,5 \%$ são de rodovias não pavimentadas. A Confederação Nacional dos Transportes (CNT, 2020) confirma $1.720 .035 \mathrm{~km}$ de rodovias construídas ou planejadas, dos quais $78,4 \%$ (1.349.125 km) são de rodovias não pavimentadas.

Estradas de terra são aqui entendidas como aquelas vias desprovidas de pavimento e cuja superfície de tráfego é constituída pelo próprio solo local, ou por revestimento primário. Geralmente estas estradas derivam de precários caminhos e trilhas pré-existentes, edificados sem projeto, sem as técnicas e os controles construtivos adequados, e sem o conjunto de medidas e ações relativo à gestão ambiental.

A função preliminar das estradas de terra é interligar pequenas propriedades rurais, de maneira a facilitar o escoamento da produção rural e os acessos aos serviços públicos de assistência social. O incremento da produção e da mobilidade resulta, geralmente, na consolidação destas vias e, por vezes, na sua pavimentação. Estes melhoramentos podem ser acompanhados por ajustes no traçado e na seção da via. Em muitos casos, os serviços de controle e gestão ambiental tornam-se compulsórios apenas nesta fase de melhoramentos. Esta percepção resulta da pequena ação de controle ambiental imposta pelos agentes públicos sobre as estradas de terra. Assim, os impactos produzidos naquela fase preliminar são cumulativos e assumem feições de passivo para a etapa seguinte.

Dentre os potenciais impactos negativos resultantes da implantação de estradas de terra, destacam-se: fragmentação de ambientes; processos precoces de erosão e assoreamento; obstrução de cursos e corpos d'água; supressão de vegetação e ressecamento de borda (precipita queimadas); dessecamento do lençol freático e alteração do balanço hídrico. A ocupação desordenada das faixas lindeiras à via, na fase de operação, também implica volume considerável de impactos.

Mas comumente no Brasil, apenas a etapa de pavimentação da estrada está sujeita ao licenciamento ambiental (LA) - procedimento administrativo no qual o poder público, representado pelos órgãos ambientais, avalia se o projeto está em observância às normas ambientais vigentes, garantindo a adoção de medidas de mitigação, controle e compensação dos eventuais impactos decorrentes. Por analogia, estima-se que aproximados $78,4 \%$ da malha rodoviária brasileira (equivalentes às vias não pavimentadas) parecem excluídas ou distantes dos processos de gestão ambiental regulares. 
O LA foi instituído no Brasil pela Lei 6.938/81 que contempla a Política Nacional do Meio Ambiente (PNMA) e que atribui ao Conselho Nacional do Meio Ambiente (CONAMA) a elaboração de normas destinadas a preservar o meio ambiente (BRASIL, 1981). A Resolução CONAMA 01/86 tipifica as estradas com duas ou mais faixas de rolamento como empreendimentos causadores de potenciais impactos ambientais significativos e, portanto, sujeitos ao licenciamento ambiental (LA), com apresentação obrigatória de Estudo de Impacto Ambiental e respectivo Relatório de Impacto Ambiental (EIA/RIMA) (BRASIL, 1986). As demais estradas integram o rol dos empreendimentos sujeitos ao LA, de acordo com a Resolução CONAMA 237/1997, mas, não necessariamente com elaboração obrigatória de EIA/RIMA (BRASIL, 1997).

Nesse sentido, cada órgão responsável pelo LA em cada uma das Unidades da Federação (UFs) deve definir as regras específicas para os vários empreendimentos, incluindo os estudos ambientais necessários. Acontece que estradas pioneiras ou de penetração, as estradas secundárias ou vicinais e as suas derivações conceituais congêneres são usualmente estradas de terra. E nestes casos, independente da largura da plataforma rodante, não é possível determinar nem indicar claramente as faixas de rolamento. De fato, observam-se nestas vias as marcações das trilhas de rodas (geralmente duas) sem a definição clara da faixa de tráfego.

Com base neste cenário, a implantação de estradas de terra demanda medidas específicas (além das normas jurídicas) quanto aos estudos ambientais complementares às fases de licenciamento. Este conjunto de medidas e os seus desdobramentos respectivos são definidos pelo órgão responsável pelo LA nas diversas UFs do país.

Neste trabalho analisam-se as legislações e os procedimentos que orientam a gestão ambiental das estradas de terra no Brasil, com o propósito de promover boas práticas de gestão e implementar medidas de proteção ambiental eficazes.

\section{OBJETIVO}

O objetivo deste trabalho é investigar os procedimentos adotados pelas UFs do Brasil para realizar o licenciamento ambiental de estradas de terra e analisar as respectivas normas jurídicas que orientam tal processo.

\section{METODOLOGIA}

A obtenção de documentos, registros oficiais, instruções normativas e legislações vigentes foi realizada, inicialmente, por meio de uma consulta aos sites dos órgãos ambientais em cada uma das UFs. Nessa etapa, buscou-se por informações quanto ao LA de estradas de terra e estradas em geral, dado que nem sempre poderiam existir informações específicas para a categoria "estradas de terra". As informações cadastradas nos sites foram complementadas por meio de contato telefônico direto com os gestores dos órgãos ambientais responsáveis pelo LA. O contato direto com alguns estados foi especialmente difícil, destacando-se: Acre (AC), Alagoas (AL), Maranhão (MA), Rondônia (RO), e Roraima (RR).

Com o intuito de obter informações mais específicas sobre o tema, foi elaborado um questionário com perguntas objetivas sobre o LA de estradas de terra (modelo Anexo). Este questionário (no modelo dos formulários Google) foi direcionado (via e-mail) aos gestores dos órgãos ambientais de cada UF do Brasil. Mas o retorno com respostas ao questionário até março 
de 2020 foi extremamente baixo. Das 27 UFs houve adesão de apenas 10. Os instrumentos de coleta de dados aplicados neste trabalho estão resumidos no Quadro 1.

Quadro 1: Instrumentos utilizados para a coleta de dados.

\begin{tabular}{|c|c|c|}
\hline $\begin{array}{l}\text { Instrumentos de } \\
\text { coleta de dados }\end{array}$ & $\begin{array}{l}\text { Conteúdo da coleta de } \\
\text { dados }\end{array}$ & Finalidade do instrumento de coleta de dados \\
\hline $\begin{array}{l}\text { Consulta aos sites } \\
\text { dos órgãos do } \\
\text { meio ambiente }\end{array}$ & $\begin{array}{l}\text { Consultas às páginas oficiais } \\
\text { na internet dos respectivos } \\
\text { órgãos ambientais em cada } \\
\text { UF. }\end{array}$ & $\begin{array}{l}\text { Por meio das legislações e normas jurídicas } \\
\text { encontradas, foi possível compor um panorama } \\
\text { da gestão ambiental aplicada em } \\
\text { empreendimentos rodoviários no Brasil. }\end{array}$ \\
\hline $\begin{array}{l}\text { Contato direto por } \\
\text { telefone }\end{array}$ & $\begin{array}{l}\text { Entrevistas com os } \\
\text { responsáveis técnicos do } \\
\text { setor de licenciamento } \\
\text { ambiental de cada UF. }\end{array}$ & $\begin{array}{l}\text { Obter dados e informações sobre o } \\
\text { licenciamento ambiental de estradas de terra } \\
\text { diretamente com os gestores dos órgãos } \\
\text { ambientais competentes. }\end{array}$ \\
\hline $\begin{array}{l}\text { Documentos e } \\
\text { referências }\end{array}$ & $\begin{array}{l}\text { Foram utilizados glossários } \\
\text { e manuais técnicos das } \\
\text { entidades licenciadoras. } \\
\text { Bem como bibliografias, } \\
\text { livros e artigos acadêmicos } \\
\text { que abrangem o tema. }\end{array}$ & $\begin{array}{c}\text { O estudo dos documentos foi fundamental para } \\
\text { o embasamento teórico sobre a tipologia das } \\
\text { estradas, além de maior compreensão sobre a } \\
\text { normatização associada à implantação de } \\
\text { estradas de terra e suas condicionantes } \\
\text { ambientais. }\end{array}$ \\
\hline $\begin{array}{l}\text { Questionário } \\
\text { aplicado a cada } \\
\text { instituição de } \\
\text { meio ambiente }\end{array}$ & $\begin{array}{l}\text { Aplicação de questionário } \\
\text { com seis perguntas } \\
\text { objetivas sobre o } \\
\text { licenciamento ambiental de } \\
\text { estradas de terra. }\end{array}$ & $\begin{array}{l}\text { O questionário permitiu obter informações mais } \\
\text { específicas acerca dos procedimentos-padrões } \\
\text { adotados em cada órgão ambiental licenciador, } \\
\text { completando as informações coletadas pelos } \\
\text { outros métodos utilizados. }\end{array}$ \\
\hline
\end{tabular}

Fonte: Elaborado pelo autor, 2020.

\section{RESULTADOS}

O Quadro 2 indica os órgãos ambientais responsáveis pelo licenciamento ambiental nas diversas UFs do Brasil. 


\section{Revista Científica ANAP Brasil}

ISSN 1984-3240 - Volume 13, número 31, 2020

Quadro 2: Órgãos estaduais responsáveis pelo licenciamento ambiental.

\begin{tabular}{|c|c|c|}
\hline $\mathbf{U F}$ & Órgãos & Siglas \\
\hline $\mathrm{AC}$ & Instituto de Meio Ambiente do Acre & IMAC \\
\hline $\mathrm{AM}$ & Instituto de Proteção Ambiental do Amazonas & IPAAM \\
\hline $\mathrm{AL}$ & Instituto do Meio Ambiente de Alagoas & IMA-AL \\
\hline $\mathrm{AP}$ & Instituto do Meio Ambiente e de Ordenamento Territorial do Amapá & IMAP \\
\hline BA & Instituto do Meio Ambiente e Recursos Hídricos & INEMA \\
\hline $\mathrm{CE}$ & Secretaria de Estado do Meio Ambiente do Ceará & SEMA-CE \\
\hline DF & Instituto Brasilia Ambiental & IBRAM \\
\hline ES & Instituto Estadual de Meio Ambiente e Recursos Hídricos & IEMA \\
\hline GO & Secretaria de Meio Ambiente, Recursos Hídricos, Infraestrutura, Cidades e assuntos Metropolitanos & SECIMA GO \\
\hline MA & Secretaria de Estado de Meio Ambiente e Recursos Naturais & SEMA-MA \\
\hline MG & Secretaria Estadual de Meio Ambiente e Desenvolvimento Sustentável & SEMAD \\
\hline MS & Instituto de Meio Ambiente do Mato Grosso do Sul & IMASUL \\
\hline MT & Secretaria de Estado do Meio Ambiente do Mato Grosso & SEMA-MT \\
\hline PA & Secretaria de Estado de Meio Ambiente e Sustentabilidade & SEMAS \\
\hline PB & Superintendência de Administração do Meio Ambiente & SUDEMA PB \\
\hline $\mathrm{PE}$ & Agência Estadual de Meio Ambiente e Recursos Hídricos de Pernambuco & CPRH PE \\
\hline PI & Secretaria do Meio Ambiente e Recursos Hídricos do Piauí & SEMAR PI \\
\hline PR & Instituto do Meio Ambiente do Paraná & IAP \\
\hline RJ & Instituto Estadual do Ambiente do Rio de Janeiro & INEA \\
\hline $\mathrm{RN}$ & Instituto de Desenvolvimento Sustentável e Meio Ambiente do Rio Grande do Norte & IDEMA-RN \\
\hline RO & Secretaria de Estado do Desenvolvimento Ambiental de Rondônia & SEDAM-RO \\
\hline RR & Fundação Estadual do Meio Ambiente e Recursos Hídricos & FEMARH \\
\hline RS & Fundação Estadual de Proteção Ambiental Henrique Luis Roessler & FEPAM \\
\hline $\mathrm{SC}$ & Instituto do Meio Ambiente de Santa Catarina & IMA-SC \\
\hline SP & Companhia Ambiental do Estado de São Paulo & CETESB \\
\hline SE & Administração Estadual do Meio Ambiente & ADEMA \\
\hline TO & Instituto Natureza do Estado do Tocantins & NATURATINS \\
\hline
\end{tabular}

Fonte: Elaborado pelo autor, 2020.

A legislação e as normas que dispõem sobre o licenciamento ambiental em cada unidade da federação estão discriminados no Quadro 3. Os dados obtidos foram cadastrados e analisados. Desta forma, foi possível elaborar um panorama geral de como a gestão ambiental é abordada e aplicada à construção civil no Brasil, notadamente nos empreendimentos rodoviários. É possível observar que a maioria das normas jurídicas encontradas está relacionada à gestão ambiental de estradas e rodovias em geral, sem abordar especificamente o seu LA. Da mesma forma, também se registra a carência ou falta de disponibilidade de documentos específicos quanto a implantação de estradas de terra. Neste sentido, são mais comuns os dados e as informações sobre as medidas relativas às fases de pavimentação, duplicação e restauração de rodovias. 
Quadro 3: Órgãos licenciadores e suas respectivas legislações sobre LA.

\begin{tabular}{|c|c|c|}
\hline $\mathbf{U F}$ & Siglas & Legislações e normas que dispõem sobre licenciamento ambiental de estradas \\
\hline $\mathrm{AC}$ & IMAC & Anexos I e II da Resolução CEMACT n ${ }^{\circ}$ 2, de 30 de setembro de 2011 \\
\hline $\mathrm{AL}$ & IMA-AL & Resolução CEPRAM n ${ }^{\circ} 170$, de 01 de setembro de 2015 \\
\hline$\overline{\mathrm{AM}}$ & IPAAM & Lei Estadual n ${ }^{\circ} 3785$, de 24 de julho de 2012 \\
\hline $\mathrm{AP}$ & IMAP & Resolução COEMA n 01, de 10 de junho de 1999 \\
\hline BA & INEMA & Resolução CEPRAM no 3.064, 22 de novembro de 2002 \\
\hline$\overline{\mathrm{CE}}$ & SEMA-CE & Resolução COEMA n ${ }^{\circ}$ 04, de 12 de abril de 2012 \\
\hline$\overline{\mathrm{DF}}$ & IBRAM & Decreto Estadual n ${ }^{\circ} 17.805$, de 05 de novembro de 1996 \\
\hline ES & IEMA & Instrução Normativa IEMA n ${ }^{\circ} 05$, de 09 de agosto de 2010 \\
\hline GO & SECIMA GO & Resolução CEMAM nº 02, DE 29 de julho de 2016 \\
\hline MA & SEMA-MA & Portaria SEMA no 123 , de 06 de novembro de 2015 \\
\hline MG & SEMAD & Deliberação Normativa n ${ }^{\circ} 74$, de 09 de setembro de 2004 \\
\hline MS & IMASUL & 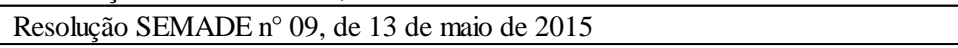 \\
\hline MT & SEMA-MT & Resolução CONSEMA n ${ }^{\circ} 85$, de 24 de setembro de 2014 \\
\hline $\mathrm{PA}$ & SEMAS & Resolução COEMA n ${ }^{\circ} 85$, de 09 de agosto de 2010 \\
\hline PB & SUDEMA PB & Deliberação COPAM n ${ }^{\circ} 3716$, de 13 de abril de 2017 \\
\hline PE & CPRH PE & Lei Estadual n ${ }^{\circ} 14.549$, de 21 de dezembro de 2011 \\
\hline PI & SEMAR PI & Resolução CONSEMA n ${ }^{\circ} 10$, de 25 de novembro de 2009 \\
\hline PR & IAP & 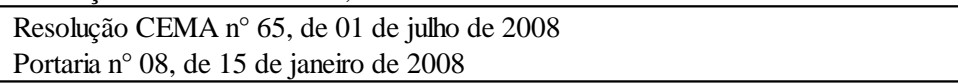 \\
\hline$\overline{\mathrm{RJ}}$ & INEA & Lei Estadual n ${ }^{\circ} 1.356$, de 03 de outubro de 1988 \\
\hline $\mathrm{RN}$ & IDEMA-RN & Resolução CONEMA n $^{\circ}$ 04, de 12 de dezembro de 2006 \\
\hline $\mathrm{RO}$ & SEDAM-RO & Lei Estadual no 890, de 24 de abril de 2000. \\
\hline$\overline{\mathrm{RR}}$ & FEMARH & Instrução Normativa FEMARH n ${ }^{\circ}$ 01, de 28 de abril de 2014 \\
\hline RS & FEPAM & Resolução CONSEMA n ${ }^{\circ} 372$, de 02 de março de 2018 \\
\hline \multirow{2}{*}{$\mathrm{SC}$} & \multirow{2}{*}{ IMA-SC } & Resolução CONSEMA n 98, de 05 de julho de 2017 \\
\hline & & 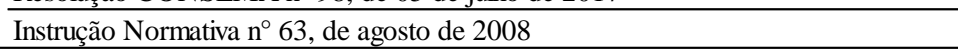 \\
\hline \multirow{3}{*}{ SP } & \multirow{3}{*}{ CETESB } & Resolução SMA n ${ }^{\circ} 33$, de 10 de setembro de 2002 \\
\hline & & Decreto Estadual n ${ }^{\circ} 53.146$, de 20 de julho de 2008 \\
\hline & & Resolução Conjunta SMA/ST n ${ }^{\circ} 04$, de 27 de março de 2010 \\
\hline $\begin{array}{l}\mathrm{SE} \\
\end{array}$ & ADEMA & Resolução CEMA no 6,29 de de julho de 2008 \\
\hline TO & NATURATINS & Instrução Normativa n ${ }^{\circ} 01$, de 10 de maio de 2017 \\
\hline
\end{tabular}

Fonte: Elaborado pelo autor, 2020.

Os Quadros 4 e 5 resumem as informações resultantes da segunda etapa dos levantamentos. Elas, portanto, equivalem às respostas aos questionários enviados e posteriormente respondidos pelos gestores ambientais. Das 27 UFs consultadas efetivadas, houve respostas em 10 casos: Amapá (AP), Bahia (BA), Distrito Federal (DF), Espírito Santo (ES), Mato Grosso (MT), Minas Gerais (MG), Pará (PA), Rio Grande do Sul (RS), Santa Catarina (SC) e São Paulo (SP).

Nota. "Normas jurídicas" é um termo generalista para a existência (ou não) de legislação estadual específica e inclui outros tipos de ordenação jurídica. Sem informações (S/I). 
Revista Científica ANAP Brasil

ISSN 1984-3240 - Volume 13, número 31, 2020

Quadro 4: Órgãos licenciadores e as respectivas informações obtidas mediante as respostas do questionário.

\begin{tabular}{|c|c|c|c|c|c|}
\hline $\begin{array}{c}\text { Aspectos } \\
\text { Analisados }\end{array}$ & AMAPÁ (AP) & Bahia (BA) & $\begin{array}{c}\text { Distrito } \\
\text { Federal (DF) }\end{array}$ & $\begin{array}{l}\text { Espírito Santo } \\
\text { (ES) }\end{array}$ & Mato Grosso (MT) \\
\hline $\begin{array}{c}\text { Principais } \\
\text { órgãos } \\
\text { licenciadores }\end{array}$ & IMAP & INEMA & IBRAM & IEMA & SEMA - MT \\
\hline $\begin{array}{c}\text { Nomenclatura } \\
\text { de estradas } \\
\text { adotada }\end{array}$ & $\begin{array}{l}\text { Estradas de } \\
\text { terra. }\end{array}$ & $\begin{array}{l}\text { Estradas de } \\
\text { terra. }\end{array}$ & $\begin{array}{l}\text { Estradas de } \\
\text { terra. }\end{array}$ & $\begin{array}{c}\text { Estradas de } \\
\text { terra. }\end{array}$ & Estradas de terra. \\
\hline Exigência de LA & Sim & Sim & Sim & Sim & Sim \\
\hline $\begin{array}{c}\text { Subordinados } \\
\text { ao controle } \\
\text { ambiental? }\end{array}$ & Não & Não & Não & Não & Não \\
\hline $\begin{array}{l}\text { Normas } \\
\text { jurídicas }\end{array}$ & $\begin{array}{c}\text { Decreto } \\
\text { Estadual } \\
3009 / 1998\end{array}$ & $\begin{array}{c}\text { Resolução } \\
\text { CEPRAM } \\
3.064 / 2002\end{array}$ & Não & $\begin{array}{c}\text { Instrução } \\
\text { Normativa } \\
\text { IEMA no } \\
\text { 005/2010 }\end{array}$ & $\begin{array}{c}\text { Resolução } \\
\text { CONSEMA 85/2014 }\end{array}$ \\
\hline $\begin{array}{l}\text { Licenças } \\
\text { ambientais } \\
\text { requeridas }\end{array}$ & $\begin{array}{c}\text { Sem } \\
\text { informações } \\
\text { (S/I). }\end{array}$ & $\begin{array}{c}\text { Licença } \\
\text { simplificada; } \\
\text { LP, LI e Lo. }\end{array}$ & (S/I). & $\begin{array}{l}\text { LP, LI e LO ou } \\
\text { Licença } \\
\text { Ambiental de } \\
\text { Regularização } \\
\text { (LAR). }\end{array}$ & (S/I). \\
\hline $\begin{array}{l}\text { Documentos e } \\
\text { estudos que } \\
\text { podem ser } \\
\text { exigidos }\end{array}$ & $(S / I)$ & $\begin{array}{c}\text { AIA e } \\
\text { EIA/RIMA. }\end{array}$ & (S/I). & $\begin{array}{c}\text { RCA (Relatório } \\
\text { de Controle } \\
\text { Ambiental) e } \\
\text { EIA/RIMA }\end{array}$ & $(S / I)$. \\
\hline $\begin{array}{c}\text { Municípios que } \\
\text { realizam LA }\end{array}$ & $\begin{array}{l}\text { Macapá, } \\
\text { Santana, } \\
\text { Ferreira } \\
\text { Gomes, Porto } \\
\text { Grande, } \\
\text { Oiapoque, } \\
\text { Laranjal do } \\
\text { Jari, Pedra } \\
\text { Branca, Serra } \\
\text { do Navio e } \\
\text { Calçoene. }\end{array}$ & Não & Não & Não & $\begin{array}{l}\text { Cuiabá, Várzea } \\
\text { Grande, } \\
\text { Rondonópolis, } \\
\text { Sinop, Lucas do Rio } \\
\text { Verde, Sorriso, Nova } \\
\text { Mutum, Barra do } \\
\text { Garças, Tangará da } \\
\text { Serra, Campo Novo } \\
\text { dos Parecis, Alta } \\
\text { Floresta, Água Boa. }\end{array}$ \\
\hline
\end{tabular}

Fonte: Elaborado pelo autor, 2020. 
Revista Científica ANAP Brasil

ISSN 1984-3240 - Volume 13, número 31, 2020

Quadro 5: Continuação das informações obtidas mediante as respostas do questionário.

\begin{tabular}{|c|c|c|c|c|c|}
\hline $\begin{array}{c}\text { Aspectos } \\
\text { Analisados }\end{array}$ & $\begin{array}{c}\text { Minas Gerais } \\
\text { (MG) }\end{array}$ & Pará (PA) & $\begin{array}{c}\text { Rio Grande do } \\
\text { Sul (RS) }\end{array}$ & $\begin{array}{c}\text { Santa Catarina } \\
\text { (SC) }\end{array}$ & São Paulo (SP) \\
\hline $\begin{array}{c}\text { Principais } \\
\text { órgãos } \\
\text { licenciadores }\end{array}$ & SEMAD & $\begin{array}{l}\text { SEMAS } \\
\text { SETRAN }\end{array}$ & FEPAM & IMA - SC & $\begin{array}{c}\text { CETESB, DAEE, } \\
\text { EDA }\end{array}$ \\
\hline $\begin{array}{c}\text { Nomenclatur } \\
\text { a de estradas } \\
\text { adotada }\end{array}$ & $\begin{array}{c}\text { Estradas de } \\
\text { terra. }\end{array}$ & $\begin{array}{c}\text { Estradas de } \\
\text { terra. }\end{array}$ & $\begin{array}{c}\text { Estradas não } \\
\text { pavimentadas. }\end{array}$ & $\begin{array}{c}\text { Estradas não } \\
\text { pavimentadas. }\end{array}$ & Estradas rurais. \\
\hline $\begin{array}{c}\text { Exigência de } \\
\text { LA }\end{array}$ & $\begin{array}{c}\text { Não. Essas } \\
\text { estradas são } \\
\text { passíveis de LA } \\
\text { se servem para } \\
\text { transporte de } \\
\text { minério e são } \\
\text { externas a } \\
\text { empreendimen } \\
\text { tos minerários. }\end{array}$ & Sim & Sim & Sim & Não \\
\hline $\begin{array}{c}\text { Subordinadas } \\
\text { a Controle } \\
\text { Ambiental? }\end{array}$ & $\begin{array}{c}\text { Autorização } \\
\text { para } \\
\text { intervenção em } \\
\text { recursos } \\
\text { hídricos, } \\
\text { supressão de } \\
\text { vegetal nativa } \\
\text { e em áreas de } \\
\text { preservação } \\
\text { permanente. }\end{array}$ & Não & Não & Não & $\begin{array}{l}\text { Apenas em casos } \\
\text { de supressão } \\
\text { vegetal, } \\
\text { adequação de } \\
\text { questões de } \\
\text { conservação do } \\
\text { solo e erosão, e } \\
\text { interferência em } \\
\text { recursos hídricos. }\end{array}$ \\
\hline $\begin{array}{l}\text { Normas } \\
\text { jurídicas }\end{array}$ & Não & Não & $\begin{array}{l}\text { Resolução } \\
\text { CONSEMA } \\
372 / 2018\end{array}$ & $\begin{array}{c}\text { Instrução } \\
\text { Normativa IN } \\
\text { 63/2018; } \\
\text { Resolução } \\
\text { CONSEMA } \\
\text { 98/2017. }\end{array}$ & Não \\
\hline $\begin{array}{c}\text { Licenças } \\
\text { ambientais } \\
\text { requeridas }\end{array}$ & (S/I). & (S/I). & LP, LI, LO. & LP, LI, LO. & $(S / I)$. \\
\hline $\begin{array}{l}\text { Documentos } \\
\text { e estudos } \\
\text { que podem } \\
\text { ser exigidos }\end{array}$ & (S/I). & $\begin{array}{l}\text { Emissão de } \\
\text { Termo de } \\
\text { Referência }\end{array}$ & (S/I). & $\begin{array}{l}\text { EAS, RAP, } \\
\text { EIA/RIMA. }\end{array}$ & (S/I). \\
\hline $\begin{array}{c}\text { Municípios } \\
\text { que realizam } \\
\text { LA }\end{array}$ & Não & Não & $\begin{array}{c}492 \\
\text { municípios, } \\
\text { dentre os } 497 \\
\text { do Estado }\end{array}$ & Não & Não \\
\hline
\end{tabular}

Fonte: Elaborado pelo autor, 2020.

Com base na análise discriminada dos dados, dentre as 10 UFs que retornaram os questionários, apenas MG e SP não realizam o LA de estradas de terra. Entretanto, ambos estados apresentam medidas de controle ambiental específicas, conforme a área de influência e a abrangência dos impactos gerados pela implantação dessas vias. Desta forma, em Minas Gerais, a obtenção de autorizações prévias que antecedem a implantação ou construção das estradas de terra é 


\section{Revista Científica ANAP Brasil}

ISSN 1984-3240 - Volume 13, número 31, 2020

essencial para os casos em que há intervenção ambiental em recursos hídricos. O conjunto de medidas e operações previsto em Minas Gerais inclui, por exemplo, a construção de obras de arte para proteger os corpos d'água. A mesma autorização também deve ser solicitada em casos de supressão vegetal nativa e interferências em áreas de preservação permanente. Além disso, quando as estradas estão inseridas em outros empreendimentos, deve haver cuidado especial com a manutenção de drenagem para evitar o carreamento de sólidos e a poeira. Dentre as medidas mitigadoras previstas neste caso, cita-se a aspersão de água.

No estado de SP, assim como em MG, há controle ambiental de estradas de terra (identificadas aqui como estradas rurais). Mas o controle em São Paulo é feito de maneira descentralizada e compartilhada por três órgãos diferentes, de acordo com o nível de interferência e o passivo ambiental gerado. Assim, cabe ao Departamento de Águas e Energia Elétrica (DAEE) determinar as medidas e os documentos para a implantação de estradas de terra e suas obras de arte, quando há uso ou interferências em corpos d'água. A critério da Companhia Ambiental do Estado de São Paulo (CETESB) é definido o controle ambiental para estradas de terra que produzam supressão vegetal e interfiram em áreas de preservação permanente. Por fim, os casos envolvendo questões de conservação do solo e impactos como a erosão devido às estradas terra, ficarão a critério do Escritório de Defesa Agropecuária (EDA).

À exceção do DF e PA, todas as UFs que relataram realizar o licenciamento de estradas de terra, citaram a respectiva legislação que orienta tal processo.

Nos estados do AP e do MT, o Decreto Estadual 3009/1998 e a Resolução CONSEMA 85/2014, apenas fazem alusão respectivamente a "Rodovias e ferrovias" e "Construção de estradas municipais" que possam causar impactos, de acordo com a sua extensão em quilômetros e com o seu potencial poluidor/degradador.

No RS, embora haja a obrigatoriedade do LA, a ordenação jurídica acerca desse processo relata que o estado não separa as estradas pavimentadas daquelas definidas como estradas não pavimentadas, que englobam as estradas de terra. Significa que de modo genérico, a licença de operação (LO) deve ser emitida para o conjunto de estradas, enquanto as licenças prévia (LP) e de instalação (LI), são emitidas para a ampliação da pavimentação.

No estado da BA, a Resolução CEPRAM 3064/2002 orienta a "Implantação/construção de novos empreendimento rodoviários", definindo a emissão de licenças padrões (LP, LI, LO) ou de uma Licença Simplificada para empreendimentos de pequeno porte (função da extensão da via em quilômetros). Ademais, os empreendimentos com porte excepcional são submetidos a Avaliação de Impacto Ambiental (AIA) por meio da elaboração de um Estudo de Impacto Ambiental e Relatório de Impacto Ambiental (EIA/RIMA).

Os resultados também evidenciam que somente o ES e SC, por meio das Instruções Normativas IEMA 05/2010 e IN 63/2018, respectivamente, estabelecem uma gama de documentações e procedimentos para realizar o licenciamento das estradas de terra.

É relevante salientar que as Normas Jurídicas do ES descrevem os procedimentos tradicionalmente utilizados para licenciar a "Implantação de estradas e rodovias". E esta classificação das vias (estradas e rodovias) é definida pelo órgão ambiental, em que as estradas de terra estão supostamente inseridas. Desta forma, o ordenamento jurídico atua de modo a indicar as licenças padrões (LP, LI, LO) ou a Licença Ambiental de Regularização (LAR), requeridas para as respectivas etapas de concepção, implantação e operação das vias. Além disso, os 


\section{Revista Científica ANAP Brasil}

ISSN 1984-3240 - Volume 13, número 31, 2020

estudos ambientais que acompanham cada fase de licenciamento são determinados mediante o potencial de impacto e a extensão da via em quilômetros. Deste modo, podem ser requeridos desde estudos mais simplificados como Relatório de Controle Ambiental (RCA), até estudos mais detalhados para vias que causem impactos ambientais significativos, como um EIA/RIMA. Finalmente, verifica-se que o órgão licenciador do estado de SC (IMA), utiliza a IN 63/2018 como o instrumento regulador. A IN 63/2018 é composta por uma gama de documentos específicos para o LA da atividade de "Implantação pioneira de estradas públicas ou operação de rodovias (exceto as vicinais), com ou sem pavimentação". Dessa maneira, com base no porte das estradas (função da sua extensão em quilômetros), é definida a execução de um Relatório Ambiental Preliminar (RAP), Estudo Ambiental Simplificado (EAS) ou EIA/RIMA.

\section{CONCLUSÕES}

A maioria das UFs brasileiras aborda a gestão ambiental de suas estradas de maneira vaga, se apropriando de nomenclaturas genéricas e pouco específicas para definir os procedimentos de LA de vias, como as estradas de terra. De um modo geral, observou-se que foi priorizada a gestão ambiental associada às atividades de restauração, duplicação e pavimentação de empreendimentos rodoviários, em detrimento das etapas de sua concepção e implantação.

A maioria das UFs que relataram realizar o licenciamento de estradas de terra citou a respectiva legislação que orientaria tal processo. Entretanto, na maioria dos casos, o conteúdo dessa legislação não abordava especificamente o LA de estradas de terra. Nesse sentido, as normativas adotadas por ES e SC foram as que mais se aproximaram do propósito de ordenação do LA de estradas terra.

Do conjunto das ações e procedimentos adotados para o licenciamento ambiental específico das estradas de terra, objeto deste trabalho, parece evidente que aquele adotado no estado de Santa Catarina é o mais apropriado.

\section{REFERÊNCIAS BIBLIOGRÁFICAS}

ACRE. Resolução CEMACT no 002, de 30 de setembro de 2011. Dispõe sobre a metodologia de enquadramento do nível de complexidade para o licenciamento ambiental de obras de infraestrutura. Diário Oficial do Estado do Acre - DOE/AC. Rio Branco, AC. 2011.

ALAGOAS. Resolução CEPRAM no 170, de 10 de agosto de 2015. Dispõe sobre processos de Licenciamento Ambiental de empreendimentos considerados os critérios de porte, potencial poluidor e natureza da atividade sendo de pequeno e médio de potencial de impacto ambiental e de baixa e média magnitude (porte). Diário Oficial do Estado do Alagoas - DOE/AL. Maceió, AL. 2015.

AMAPÁ. Resolução COEMA no 01, de 10 de junho de 1999. Estabelece diretrizes para caracterização de empreendimentos potencialmente causadores de degradação ambiental, licenciamento ambiental e dá outras providências. Diário Oficial do Estado de Amapá - DOE/AP. Macapá, AP. 1999.

AMAZONAS. Lei no 3785, de 24 de julho de 2012. Dispõe sobre o licenciamento ambiental no Estado do Amazonas, revoga a Lei 3.219, de 28 de dezembro de 2007, e dá outras providências. Diário Oficial do Estado de Amazonas DOE/AM. Amazonas, AM. 2012

BAHIA. Resolução CEPRAM no 3.064, de 22 de novembro de 2002. Aprova a Norma Técnica NT- 007 e seus Anexos I e II, que dispõe sobre o Processo de Licenciamento Ambiental de Empreendimentos Rodoviário1s e Vias de Acesso, no Estado da Bahia. Diário Oficial do Estado da Bahia - DOE/BA. Salvador, BA. 2002.

BRASIL. Lei no 6.938 de 31 de agosto de 1981. Dispõe sobre a Política Nacional do Meio Ambiente, seus fins e mecanismos de formulação e aplicação, e dá outras providência. Diário Oficial da União. Brasília, DF. 1981. 
CARVALHO, Juliana Bartles. Licenças Ambientais de Estradas Parque: 0 caso da estrada Nequinho Fogaça. $49 \mathrm{f}$. Trabalho de Conclusão de Curso - Universidade Estadual Paulista, Faculdade de Engenharia, Ilha Solteira, SP. 2018.

CEARÁ. Resolução COEMA no 04, de 12 de abril de 2012. Dispõe sobre a atualização dos procedimentos, critérios, parâmetros e custos aplicados aos processos de licenciamento e autorização ambiental no âmbito da Superintendência Estadual do Meio Ambiente - SEMACE. Diário Oficial do Estado de Ceará - DOE/CE. Fortaleza, CE. 2012.

CNT - CONFEDERAÇÃO NACIONAL DO TRANSPORTE. Boletim Unificado 4. Boletins Técnicos. Brasília, DF, abril de 2020. 48 p.

CONAMA - Conselho Nacional do Meio Ambiente. Resolução no 01 de 23 de janeiro 1986. Dispõe sobre critérios básicos e diretrizes gerais para a avaliação de impacto ambiental. Diário Oficial da União. Brasília, DF. 1986.

CONAMA - Conselho Nacional do Meio Ambiente. Resolução no 237 de 19 de dezembro 1997. Dispõe sobre a revisão e complementação dos procedimentos e critérios utilizados para o licenciamento ambiental. Diário Oficial da União. Brasília, DF. 1997.

DISTRITO FEDERAL. Decreto no 17.805, de 05 de novembro de 1996. Estabelece os preços para análise de processos de licenciamento ambiental e dá outras providências. Diário Oficial do Distrito Federal - DO/DF. Brasília, DF. 1996.

DNER. Departamento Nacional de Estradas de Rodagem. Anuário Estatístico dos Transportes: GEIPOT. 2000. Disponível em: http://geipot.gov.br/NovaWeb/IndexAnuario.htm. Acesso em: 15 fev. 2020.

DNIT. Departamento Nacional de Infraestrutura de Transportes. Glossário de termos técnicos rodoviários. 2 ed. Publicação IPR-700. Rio de Janeiro, 2017. 324 p.

DNIT. Departamento Nacional de Infraestrutura de Transportes. Glossário de termos técnicos ambientais rodoviários. Publicação IPR-721. Rio de Janeiro, 2006. 116 p.

ESPÍRITO SANTO. Instrução Normativa no 005 de 09 de agosto de 2010. Estabelece os critérios para o licenciamento ambiental de estradas, rodovias e obras afins. Diário Oficial do Estado de Espírito Santo - DOE/ES. Vitória, ES. 2010.

GOIÁS. Resolução CEMAM no 02, de 29 de julho de 2016. Estabelece a lista de atividades de impacto ambiental local no âmbito do Estado de Goiás, dispõe sobre o credenciamento de Municípios para o licenciamento ambiental de atividades de impacto local, regulamenta a instauração de competência estadual supletiva, dispõe sobre a Corte de Conciliação de Descentralização e dá outras providências. Diário Oficial do Estado de Goiás - DOE/GO. Goiânia, GO. 2016.

IMA - Instituto do Meio Ambiente de Santa Catarina. Instrução Normativa no 63 de agosto de 2018. Florianópolis, SC. 2018.

MATO GROSSO. Resolução CONSEMA no 85 de 24 de setembro de 2014. Define as atividades, obras e empreendimentos que causam ou possam causar impacto ambiental local, fixa normas gerais de cooperação técnica entre a Secretaria de Estado de Meio Ambiente - SEMA e Prefeituras Municipais nas ações administrativas decorrentes do exercício da competência comum relativas à proteção das paisagens notáveis, à proteção do meio ambiente, ao combate à poluição em qualquer de suas formas em conformidade com o previsto na Lei Complementar no 140/2011 e dá outras providência. Diário Oficial do Estado de Mato Grosso - DOE/MT. Cuiabá, MT. 2014.

MATO GROSSO DO SUL. Resolução SEMADE no 02, de 13 de maio de 2015. Estabelece normas e procedimentos para o licenciamento ambiental Estadual, e dá outras providências. Diário Oficial do Estado de Mato Grosso do Sul - DOE/MS. Campo Grande, MS. 2015.

MARANHÃO. Portaria SEMA no 123, de 06 de novembro de 2015. Disciplina os procedimentos de Dispensa de Licenciamento Ambiental - DLA, no âmbito da Secretaria de Estado de Meio Ambiente e Recursos Naturais - Sema. Diário Oficial da União - DOU/MA. São Luís, MA. 2015. 


\title{
Revista Científica ANAP Brasil
}

\author{
ISSN 1984-3240 - Volume 13, número 31, 2020
}

MINAS GERAIS. Deliberação Normativa COPAM no 74, de 9 de setembro de 2004.Estabelece critérios para classificação, segundo o porte e potencial poluidor, de empreendimentos e atividades modificadoras do meio ambiente passíveis de autorização ou de licenciamento ambiental no nível estadual, determina normas para indenização dos custos de análise de pedidos de autorização e de licenciamento ambiental, e dá outras providências. Diário Oficial do Estado de Minas Gerais- DOE/MG. Belo Horizonte, MG. 2004.

PARÁ. Resolução COEMA no 85, 09 de agosto de 2010. Altera o Parágrafo único da Resolução COEMA no 062 , de 22 de fevereiro de 2008. Diário Oficial do Estado do Pará - DOE/PA. Belém, PA. 2010.

PARAÍBA. Deliberação COPAM no 3716, de 13 de abril de 2017. Dispõe sobre a apresentação no Licenciamento Ambiental de obras de estradas, adutoras, túneis e edificações de médio a grande porte a comprovação da origem dos agregados utilizados (Areia, Argila, Brita, pó de brita e Cascalho) para o Licenciamento Ambiental de Instalação. Diário Oficial do Estado de Paraíba - DOE/PB. João Pessoa, PB. 2017.

PARANÁ. Resolução CEMA no 65, de 01 de julho de 2008. Dispõe sobre o licenciamento ambiental, estabelece critérios e procedimentos a serem adotados para as atividades poluidoras, degradadoras e/ou modificadoras do meio ambiente e adota outras providências. Curitiba, PR. 2008.

PARANÁ. Portaria no 008, de 15 de janeiro de 2008. Estabelece critérios para licenciamento de pequenas cascalheiras de interesse de Prefeituras Municipais e Departamento de Estradas de Rodagem - DER. Curitiba, PR. 2008.

PERNAMBUCO. Lei no 14.549, de 21 de dezembro de 2011. Altera a Lei no 14.249, de 17 de dezembro de 2010, que dispõe sobre licenciamento ambiental, infrações e sanções administrativas ao meio ambiente, e dá outras providências. Diário Oficial do Estado de Pernambuco - DOE/PE. Recife, PE. 2010.

PIAUÍ. Resolução CONSEMA 10, de 25 de novembro de 2009. Estabelece critérios para classificação, segundo o porte e potencial de impacto ambiental, de empreendimentos e atividades modificadoras do meio ambiente passíveis de declaração de baixo impacto ou de licenciamento ambiental no nível estadual, determina estudos ambientais compatíveis com o potencial de impacto ambiental e dá outras providências. Diário Oficial do Estado de Piauí - DOE/PI. Teresina, PI. 2009.

RIO DE JANEIRO (Estado). Lei Estadual no 1356, de 03 de outubro de 1988. Dispõe sobre os procedimentos vinculados à elaboração, análise e aprovação dos Estudos de Impacto Ambiental. Rio de Janeiro, RJ. 1988. RIO GRANDE DO NORTE. Resolução CONEMA no 04, de 12 de dezembro de 2006. Aprova nova versão do Anexo Único da Resolução CONEMA no 4/2009. Diário Oficial do Estado do Rio Grande do Norte - DOE/RN. Natal, RN. 2006.

RIO GRANDE DO SUL. Resolução CONSEMA no 372 de 22 de fevereiro de 2018.Dispõe sobre os empreendimentos e atividades utilizadores de recursos ambientais, efetiva ou potencialmente poluidores ou capazes, sob qualquer forma, de causar degradação ambiental, passíveis de licenciamento ambiental no Estado do Rio Grande do Sul, destacando os de impacto de âmbito local para o exercício da competência municipal no licenciamento ambiental. Diário Oficial do Estado de Rio Grande do Sul - DOE/RS. Porto Alegre, RS. 2018.

RONDÔNIA. Lei Estadual no 890, de 24 de abril de 2000. Dispõe sobre procedimentos vinculados à elaboração, análise e aprovação de Estudo de Impacto Ambiental - EIA e Relatório de Impacto Ambiental - RIMA e dá outras providências. Diário Oficial do Estado de Rondônia - DOE/RO. Porto Velho, RO. 2000.

RORAIMA. Instrução Normativa FEMARH no 01, 28 de abril de 2014.Dispõe sobre os procedimentos simplificados para o Licenciamento Especial e a Regularização de Atividades e Empreendimentos realizados em Assentamentos de Reforma Agrária e áreas de até 4 módulos fiscais no estado de Roraima na Fundação Estadual do Meio Ambiente e Recursos Hídricos - FEMARH. Diário Oficial da União - DOE/RR. Boa Vista, RR. 2014.

SANTA CATARINA. Resolução CONSEMA no 98 de 05 de julho de 2017. Aprova, nos termos do inciso XIII, do art. 12, da Lei no 14.675, de 13 de abril de 2009, a listagem das atividades sujeitas ao licenciamento ambiental, define os estudos ambientais necessários e estabelece outras providências. Diário Oficial do Estado de Santa Catarina DOE/SC. Florianópolis, SC. 2017.

SÃO PAULO (Estado). Decreto no 53.146, de 20 de junho de 2008. Define os parâmetros para a implantação, gestão e operação de estradas no interior de Unidades de Conservação de Proteção Integral no Estado de São Paulo e dá providências correlatas. Diário Oficial do Estado de São Paulo - DOE/SP. São Paulo, SP. 2008. 


\title{
Revista Científica ANAP Brasil
}

\author{
ISSN 1984-3240 - Volume 13, número 31, 2020
}

SÃO PAULO (Estado). Resolução SMA no 33, de 10 de setembro de 2002. Dispõe sobre a simplificação do licenciamento ambiental das intervenções destinadas à conservação, manutenção e pavimentação de estradas vicinais que se encontrem em operação. São Paulo, SP. 2002.

SERGIPE. Resolução CEMA no 6 de 29 de julho de 2008.Dispõe sobre procedimentos administrativos do licenciamento ambiental, critérios de enquadramento e tipificação de atividades e empreendimentos potencialmente causadores da degradação ambiental e fixação de custos operacionais e de análise das licenças ambientais e autorizações. Diário Oficial do Estado de Sergipe - DOE/SE. Aracaju, SE. 2008.

SNV - SISTEMA NACIONAL DE VIAÇÃO. 2017. Disponível em: http://www.dnit.gov.br/sistema-nacional-deviacao/sistema-nacional-de-viacao. Acesso em: 07 dez. 2019.

TOCANTINS. Resolução COEMA no 07, de 09 de agosto de 2005. Dispõe sobre o Sistema Integrado de Controle Ambiental do Estado do Tocantins. Diário Oficial do Estado de Tocantins - DOE/TO. Palmas, TO. 2005 


\section{ANEXO - Questionário sobre gestão ambiental de estradas de terra}

1. Qual é a nome do órgão estadual responsável pela gestão ambiental de estradas? E qual é o estado brasileiro que ele contempla?

2. Qual é a nomenclatura utilizada para definir as estradas não pavimentadas (aquelas desprovidas de revestimento asfáltico)?
( ) Estradas de terra;
( ) Estradas vicinais;
( ) Estradas vicinais não pavimentadas;
( ) Estradas secundárias;
( ) Estradas florestais;
( ) Estradas rurais;
( ) Outro:

3. Essas estradas são objeto de licenciamento ambiental?
( ) Sim.
( ) Não.

4. Se a resposta é "não", as estradas não pavimentadas estão subordinadas a algum tipo de controle ambiental?

( ) Sim. Qual é o tipo de controle ambiental utilizado e como se procede?

\section{( ) Não.}

5. Caso sejam objeto de licenciamento ambiental, há legislação estadual específica que contemple e especifique este processo para estradas não pavimentadas?

( ) Sim. Qual é a legislação?

( ) Não. Existe alguma ordenação jurídica ou instrução normativa que as contemple? Qual?

6. Há municípios no Estado que realizem o licenciamento ambiental ou adotam alguma legislação própria para as estradas não pavimentadas?

( ) Sim. Quais os principais municípios que realizam o licenciamento ambiental?

( ) Não.

Muito obrigada pela sua contribuição! 